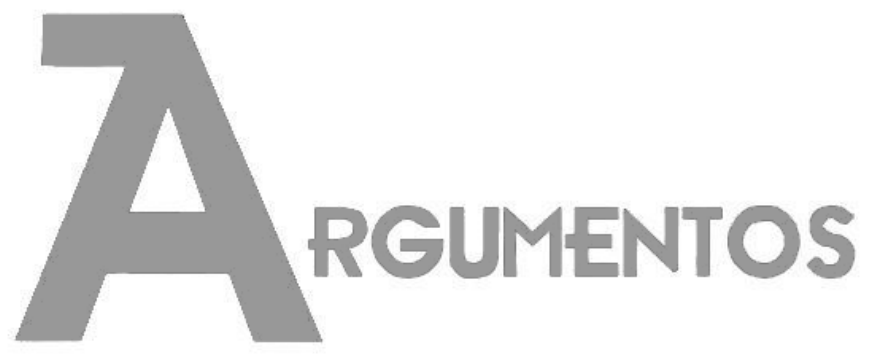

Vol. 17, n. 2, jul./dez. 2020 ISSN: 2527-2551 (online)

https://www.periodicos.unimontes.br/index.php/argumentos

\title{
Resenha
}

CARDOSO, Antônio Dimas (org). Desigualdade e reconhecimento: atualidade da teoria de Axel Honneth. Montes Claros, Editora Unimontes, 2018.

\section{Repensando a teoria crítica e sua atualidade: Honneth e seu legado teórico}

Ícaro Yure Freire de Andrade ${ }^{1}$

Recebido em: 30/09/2019

Aprovado em: 11/05/2019

Axel Honneth despontou como uma das grandes referências da teoria social crítica contemporânea e como um herdeiro direto dos problemas levantados pelos teóricos da primeira geração que vieram a ser conhecidos como pertencentes a Escola de Frankfurt. Suas análises têm influência em várias áreas de produção do conhecimento: da educação, ao serviço social, passando pelo direito e indo para a psicologia e psicanálise. Mas como herdeiro de uma grande tradição intelectual, será necessário que tracemos uma pequena biografia teórica da tradição em que está inserida para posteriormente chegarmos ao que é apresentado como contribuições a teoria social presente neste livro em que vários autores pertencentes a áreas diversas analisam seus conceitos, usos e limites.

\footnotetext{
${ }^{1}$ Doutorando em Sociologia pelo Universidade Federal da Paraíba (PPGS/UFPB), Brasil, integrante do GRESP (Grupo de Estudos em Sociologia Política) atuando na linha Emancipação, utopias e novas virtudes. E-mail: icaroyuresocio@gmail.com. ORCID: https://orcid.org/0000-0003-2311-656X.
} 
Como demonstrado por Max Horkheimer em seu artigo clássico intitulado “Teoria Tradicional e Teoria Crítica" (1937), a teoria crítica da sociedade demonstra-se totalmente avessa ao positivismo da teoria tradicional, isto é, a teoria crítica da sociedade teria como pretensão não apenas uma análise no nível conceitual acerca dos elementos organizativos da realidade social, mas também teria como objetivo pensarse enquanto potencial de mudança nessa própria realidade tendo como elemento norteador de suas análises a emancipação humana.

Diferentemente da teoria tradicional, nestes termos, a teoria crítica seria sempre ciente de seu contexto social de origem, assim como também do seu contexto de atuação política (HONNETH, 1996). E o ponto mais importante: não é uma teoria que se apresenta enquanto acabada.

Dos primeiros teóricos pertencentes a esta vertente para os contemporâneos existe uma história de debates, críticas e atualizações. Mas mantendo-se sempre em mente os elementos fundacionais desse tipo de percepção teórica: análise das estruturas de produção e reprodução da dominação e a centralidade que o horizonte normativo tem na condução dessa dominação e, posteriormente, na construção de possibilidades emancipatórias - isso está mais presente nos escritos recentes de Axel Honneth.

Theodor Adorno e Max Horkheimer ficaram conhecidos como os primeiros teóricos pertencentes à teoria crítica e também por serem os responsáveis pela confecção de uma das obras mais importantes de teoria social do final do século XIX: $A$ dialética do esclarecimento (1987). A obra traz como diagnóstico a integração total da sociedade a uma lógica sistêmica que tem como objetivo a internalização da dominação e sua reprodução através da ação dos indivíduos submetida a razão instrumental. Para estes autores era uma tendência do capitalismo no pós-guerra expandir seus imperativos não apenas para o mercado propriamente entendido enquanto tal, mas também para outras dimensões de socialização tais como a cultura - por isso, o conceito de Indústria Cultural é muito importante na compreensão geral do diagnóstico proposto em suas análises.

É a partir das respostas não acessíveis e das limitações analíticas e metodológicas presentes em A dialética do Esclarecimento que Jürgen Habermas dá continuidade as discussões levantadas pelos seus antecessores. Habermas ao criticar o fechamento das 
possibilidades de emancipação apresentados por Adorno e Horkheimer, acusa-os de negligenciarem uma dimensão importante na compreensão da Modernidade que se refere ao papel exercido pelos indivíduos na construção de formas de socialização que não obedecem totalmente a razão instrumental e tem na ação comunicativa a possibilidade de existência.

Jürgen Habermas construirá sua teoria da ação comunicativa a partir de um intepretação de suas análises sobre Friedrich Hegel, que é tido para o autor como o primeiro a

(...) apontar para a interação de universal e singular na constituição da subjetividade, e a argumentar que a subjetividade é fundamentalmente intersubjetividade, ou seja, fundamentada em reconhecimento mútuo. A inovação de Hegel mostrar que a constituição do "eu" não é uma questão da autorreflexão do "eu" solitário, mas envolve antes o acordo comunicativo de sujeitos opostos. (SINNERBRINK, 2017, p. 160)

A intersubjetividade aparece enquanto elemento constituinte da experiência da modernidade e também elemento essencial para a compreensão de uma crítica da mesma que pense possibilidades de escapar à sua lógica de dominação. Axel Honneth (2003) partirá dessa noção de que a subjetividade é resultado de um processo que é construído intersubjetivamente e diferentemente de Jürgen Habermas, apontará para a importância do conflito na construção dessa comunicação entre os indivíduos, dando ênfase dessa forma ao elemento do confronto no pensamento hegeliano. Neste sentido as formas de desrespeito e indignação moral (NOBRE, 2003) serão importantes para compreender os conflitos e disputas que são sociais, políticas mas também morais que se apresentam nos contextos da social democracia contemporânea.

Para Honneth existe uma "gramática moral" que media essas disputas, ou seja, a dimensão normativa ganha centralidade não apenas enquanto construção de uma moralidade que inclua um conjunto de sujeitos mas também que esteja interligado com a auto-estima dos sujeitos de forma individualmente e sempre em relação com a coletividade (HONNETH, 2003).

É dentro desse contexto de disputas, rupturas e continuidades teóricas que podemos situar o livro organizado por Antônio Dimas Cardoso. Apesar da centralidade das discussões girarem em torno da produção teórica de Axel Honneth, os autores que 
compõem Desigualdade e Reconhecimento: atualidade da teoria crítica de Axel Honneth sempre se referenciam a discussões e disputas teóricas pregressas, como propõem discussões posteriores tentando estabelecer relações com outros autores que não necessariamente pertencem à tradição da teoria crítica alemã, mas podem ser reconhecidos como autores de teorias críticas.

O livro é composto de onze capítulos que foram escritos por doze pesquisadores diferentes. Por mais que o título da obra se refira a teoria do reconhecimento de Honneth os autores também analisam obras mais recentes escritas pelo teórico, tais como sua atualização do socialismo enquanto uma ideia adaptável aos contextos sociais atuais.

O primeiro capítulo intitulado Exposição crítica da teoria do reconhecimento de Axel Honneth, escrito por Marco Vanzulli traz como plano de fundo um esboço conceitual da teoria do reconhecimento presente na obra do sociólogo alemão e uma discussão entre os limites interpretativos de Axel Honneth sobre a teoria de Marx. Para Vanzulli apesar da importância de suas contribuições, a teoria do reconhecimento apresentada por Honneth é uma "aporética tentativa de conciliação entre marxismo e a teoria habermasiana da ação comunicativa". (p. 29)

O segundo capítulo, Teoria crítica e psicanálise: um processo de aprendizado de Adorno, através de Habermas, até Honneth, escrito por Eleonora Piromalli discutirá as dimensões psicanalíticas presentes na obra de Theodor Adorno, Habermas e Honneth e seus limites emancipatórios. A autora destaca o "beco sem saída" emancipatório proposto por Adorno ao enunciar sua crítica a Modernidade e como o mesmo ainda está refletido nas obras de Habermas e Honneth em termos diferentes.

O terceiro e quarto capítulos, A teoria do reconhecimento de Axel Honneth: uma análise de sua proposta de atualização do socialismo e O Socialismo de Axel Honneth: da ideia à política, escritos respectivamente por Patrícia Mattos e Gonçalo Marcelo, centram-se na discussão da tentativa de atualização da ideia de socialismo proposta por Axel Honneth.

Patrícia Mattos traz críticas contundentes a perspectiva honnethiana de autorrealização, liberdade e socialismo. Para a autora, Axel Honneth erra ao propor uma reconstrução do socialismo enfatizando as conquistas institucionais, subestimando assim os mecanismos de poder social. 
Gonçalo Marcelo, por sua vez, aponta para as mudanças teóricas e de análise presentes na teoria do reconhecimento de Axel Honneth que sai do plano dos movimentos sociais e suas disputas e centra-se no desenvolvimento do que o autor chama de "instituições de reconhecimento", isto é, as instituições seriam reflexo direto das demandas normativas que emergem das disputas no campo social, político e moral tornado-as centrais na sua ideia de socialismo.

É interessante notar que tanto Patrícia Mattos, como Gonçalo Marcelo percebem a influência direta da interpretação hegeliana da intersubjetividade advinda da teoria habermasiana onde as instituições seriam diretamente refletidas como essas demandas normativas e o Estado deixando de ser um problema para se pensar a emancipação, passando dessa forma a compreender parte crucial da execução dessa ideia.

O quinto capítulo, Desenvolvimento social na teoria crítica de Honneth, escrito por Antônio Dimas Cardoso traz uma discussão à respeito da ideia de desenvolvimento social dentro da teoria do reconhecimento honnethiana - como o título sugere. Nesse sentido, é impossível compreender o reconhecimento sem concebê-lo enquanto uma forma de pensar que tem como objetivo equiparar as relações sociais e sempre renovarse através dos conflitos e disputas que compõem as dinâmicas sociais, visando desta forma a diminuição dos processos de alienação e auto-alienação.

O sexto capítulo, A teoria da justiça de Rawls e o socialismo atualizado de Honneth: crítica e contraponto ao neoliberalismo escrito por Richardson Xavier Brant, discute as possíveis contribuições de Rawls e Honneth para se pensar novas políticas de Estado de bem-estar social.

O sétimo e o oitavo capítulos, Justiça restaurativa e reconhecimento e $O$ dilema jurídico na busca por reconhecimento, escritos respectivamente por Elton Dias Xavier, Anne Marielle Castro Carvalho e Leandro Luciano da Silva, centram-se nas contribuições da teoria do reconhecimento de honnethiana para a teoria jurídica.

Elton Xavier e Anne Marielle Castro Carvalho partem da hipótese de que

(...) frente ao sistema tão segregador dos indivíduos marginalizados da sociedade, a justiça restaurativa apresenta-se como uma alternativa privilegiadora da inclusão social, da cooperação e do reconhecimento 
recíproco, por viabilizar práticas dialógicas que geram soluções mais compatíveis com a realidade dos atores afetados. (p. 197)

Já Leandro Luciano Silva apresentará as contribuições da teoria do reconhecimento de Axel Honneth para pensar o reconhecimento jurídico que se estabelece primeiro de forma individual para depois estabelecer-se de forma coletiva, tendo pelo caminho uma série de problemas referentes as disputas inerentes a gramática moral das sociedades contemporâneas.

O nono capítulo, Tudo que é líquido escorrega entre os dedos: as inconsistências das lutas de classes no processo de autoconsciência, escrito por Custódio Jovêncio Barbosa filho, tem como objetivo discutir o processo de formação da autoconsciência da classe trabalhadora, relacionando-a com o sistema econômico vigente e as possibilidades emancipatórias que daí decorrem. O autor propõe uma discussão entre Lukács e Axel Honneth.

O décimo capítulo, Lévinas: a ética como filosofia primeira e a assimetria fundamental na relação face a face, escrito por Mona Lisa Campanha Duarte Calares, propõe um dialógo crítico entra a teoria do reconhecimento de Axel Honneth e a teoria da responsabilização moral de Emannuel Lévinas. Mais do que pensar a relação entre o "eu" e o "outro", torna-se necessário inserir nessa problemática moral a presença de um terceiro que quando percebido traz o elemento da responsabilidade para dentro da necessidade do reconhecimento.

O décimo primeiro e último capítulo, Política de assistência social $e$ reconhecimento social: uma análise crítica, escrito por Jaciany Soares Serafim aponta para a importância da teoria do reconhecimento para se pensar uma assistência social que fuja de uma ideia meramente assistencialista e funcionalista e centre-se na reflexão crítica de suas ações e no fazer assistência social pensado na estima social e nas possibilidades de emancipação.

Desigualdade e reconhecimento: atualidade da teoria crítica de Axel Honneth mostra-se enquanto uma obra importante para se pensar os rumos, possibilidades e limitações dos usos da teoria crítica nas análises sociais mais diversas. É uma obra que tem como norte a discussão crítica, e também demonstra as diversas formas como a teoria de Axel Honneth foi recepcionado no Brasil. 
São ensaios e artigos de pesquisadores de diversas áreas - tais como filosofia, ciência política, ciências jurídicas, serviço social, educação - que se propõem a analisar de forma pontual a crítica as contribuições e as (im)possibilidades de compreensão e análise através da luz da teoria crítica contemporânea. Demonstrando, assim, a atualidade e importância dessa teoria para contemporaneidade.

\section{Referências}

ADORNO, Theodor.; HORKHEIMER, Max. A dialética do esclarecimento. Rio de Janeiro: Zahar, 1985.

SINNERBRINK, Robert. Hegelianismo. Rio de Janeiro: Editora Vozes, 2017.

HONNETH, Axel. Teoria crítica. In: GIDDENS, Anthony.; TURNER, Jonathan. (ORG) Teoria Social hoje. São Paulo: Editora Unesp, 1996.

HONNETH, Axel. Luta por reconhecimento: A gramática moral dos conflitos sociais. São Paulo: Editora 34, 2003. 